\title{
ДИАГНОСТИКА ИНФЕКЦИОННОЙ УРОГЕНИТАЛЬНОЙ ПАТОЛОГИИ МЕТОДОМ КОЛИЧЕСТВЕННОЙ ПЦР
}

\author{
М. Р. Рахматулина ${ }^{\otimes}$, И. С. Галкина \\ 1 Федеральный медицинский биофизический центр имени А. И. Бурназяна, Москва, Россия \\ 2 Центральный научно-исследовательский институт организации и информатизации здравоохранения Минздрава России, Москва, Россия \\ В статье представлены современные методы диагностики инфекций, передаваемых половым путем, их преимущества и недостатки, показания к \\ применению. Описаны возможности количественной полимеразной цепной реакции для диагностики воспалительных заболеваний и дисбиотических \\ состояний у мужчин и женщин. Данный метод, являющийся в настоящее время «золотым стандартом" диагностики урогенитальной патологии, \\ имеет неоспоримые преимущества перед микробиологическими методами и полимеразной цепной реакцией в качественном формате: менее \\ жесткие требования к преаналитическому этапу для сохранения количественных соотношений между микроорганизмами (нуклеиновыми кислотами \\ микроорганизмов), значительно меньший риск влияния на результат исследования контаминации образцов микроорганизмами из внешней среды, \\ равные условия по чувствительности и специфичности для всех микроорганизмов, в том числе некультивируемых и труднокультивируемых, возможность \\ контроля взятия материала и оценки состояния микробиоты по отношению микроорганизмов и их групп друг к другу, скорость получения результата и \\ возможность исследования неинвазивно взятых образцов.
}

Ключевые слова: микробный биоценоз, урогенитальные инфекции, количественная полимеразная цепная реакция

Декларации: авторы заявляют о наличии конфликта интересов в связи с аффилиацией с группой компаний «ДНК-Технология» - разработчиком и производителем упоминаемых в статье реагентов.

Информация о вкладе авторов: М. Р. Рахматулина - анализ данных литературы, написание и редактирование текста; И. С. Галкина — анализ данных литературы, написание текста.

$\varangle$ Для корреспонденции: Маргарита Рафиковна Рахматулина

Новоясеневский проспект, д. 9, г. Москва, 117588; ra.marg@yandex.ru

Статья получена: 03.12.2019 Статья принята к печати: 18.12.2019 Опубликована онлайн: 25.12.2019

DOI: 10.24075 /vrgmu.2019.088

\section{QUANTITATIVE PCR IN DIAGNOSING INFECTIOUS UROGENITAL PATHOLOGY}

Rakhmatulina MR ${ }^{1} \otimes$, Galkina IS²

${ }_{1}^{1}$ Burnasyan Federal Medical Biophysical Center of Federal Medical Biological Agency, Moscow, Russia

${ }^{2}$ Federal Research Institute for Health Organization and Informatics of Ministry of Health of the Russian Federation, Moscow, Russia

This article describes the contemporary methods of diagnosing sexually transmitted infections, their advantages and disadvantages, indications for use. The authors describe application of quantitative polymerase chain reaction in diagnosing inflammatory diseases and dysbiotic conditions in men and women. This method, which is currently the "golden standard" in urogenital pathology diagnostics, has undeniable advantages over microbiological methods and qualitative polymerase chain reaction: the preanalytical stage requirements (preservation of quantitative ratios between microorganisms or nucleic acids of microorganisms) are not as strict, the risk of contamination from outside environment and subsequent corruption of the results is significantly smaller, the conditions for all microorganisms, including those impossible and hard to cultivate, are the same sensitivity and specificity-wise, it is possible to sample materials and evaluate microbiota (ratios of microorganisms and their groups) and also possible to collect samples non-invasively, the speed of testing is high.

Keywords: microbial biocenosis, urogenital infections, QPCR

Declarations: the authors declare a conflict of interests in connection with affiliation with DNK-Tekhnologia group of companies, developer and manufacturer of the reagents mentioned in the article.

Author contribution: Rakhmatulina MR — literature data analysis, text authoring and editing; Galkina IS — literature data analysis, text authoring.

$\square$ Correspondence should be addressed: Margarita R. Rakhmatulina Novoyasenevsky Prospekt, 9, Moscow, 117588; ra.marg@yandex.ru

Received: 03.12.2019 Accepted: 18.12.2019 Published online: 25.12.2019

DOI: $10.24075 /$ brsmu.2019.088

Согласно оценкам современных исследователей, ежегодно более 357 млн людей оказываются инфицированными бактериальными возбудителями инфекций, передаваемых половым путем (ИППП) [1, 2], а частота воспалительных заболеваний урогенитального тракта, вызванных аэробными и анаэробными условно-патогенными микроорганизмами, достигает 80\% среди патологических состояний половой сореры [3-5].

С целью снижения заболеваемости и ликвидации ИППП была разработана Глобальная стратегия сектора здравоохранения по инфекциям, передаваемым половым путем (2009-2016, 2016-2021 гг.), одной из задач которой является обеспечение ранней диагностики данных заболеваний, в том числе при отсутствии симптомов у инсрицированных лиц, что создаст оптимальные условия для проведения результативного лечения и предупреждения дальнейшего распространения инфекционных агентов [2].

До недавнего времени «золотым стандартом» диагностики урогенитальных инфекций являлось культуральное исследование. Однако значительное количество этиологических агентов инфекционновоспалительных процессов урогенитального тракта является труднокультивируемым или некультивируемым. Кроме того, трудоемкость и длительность выполнения культурального исследования существенно ограничивает его применение в рутинной клинической практике, 
что требует внедрения новых технологий диагностики урогенитальной патологии.

\section{Методы диагностики урогенитальных инфекций}

В настоящее время подтверждение диагноза гонококковой инфекции на основании результатов микроскопического исследования рекомендовано только у мужчин с манифестными формами заболевания. Существенные недостатки микроскопии (субъективность оценки результата, низкая чувствительность (30-40\%) при исследовании цервикальных, фарингеальных и ректальных проб, а также при бессимптомной инфекции) ограничивают его применение [6]. При обследовании детей, беременных, женщин в период менопаузы, при подозрении на экстрагенитальные и осложненные формы заболевания необходимо использовать культуральный и/или молекулярно-биологические методы. Чувствительность и специфичность молекулярно-биологических методов для идентисикации N. gonorrhoeae достигают 100\%. Они имеют приоритетное значение в диагностике бессимптомных форм заболевания, при подозрении на микст-инфекцию, при скрининговых обследованиях, а также при наличии анамнестических и/или клинических признаков гонококковой инфекции и отрицательном результате микроскопического исследования или при наличии измененных грамотрицательных или грамвариабельных диплококков [7, 8].

В основе диагностики урогенитального трихомониаза лежат микроскопия нативного препарата, молекулярнобиологические и культуральный методы. Необходимое условие микроскопии нативного препарата - проведение исследования немедленно после получения биологического материала, что ограничивает применение данного метода. Микроскопическое исследование окрашенных препаратов не рекомендовано для диагностики, так как имеет самую низкую чувствительность и специфичность (30-60\%) относительно других лабораторных методов (влагалищная трихомонада часто представлена округлыми формами, напоминающими полиморфноядерные лейкоциты, а ее типичные морфологические признаки теряются во время фиксации и окрашивания) [6].

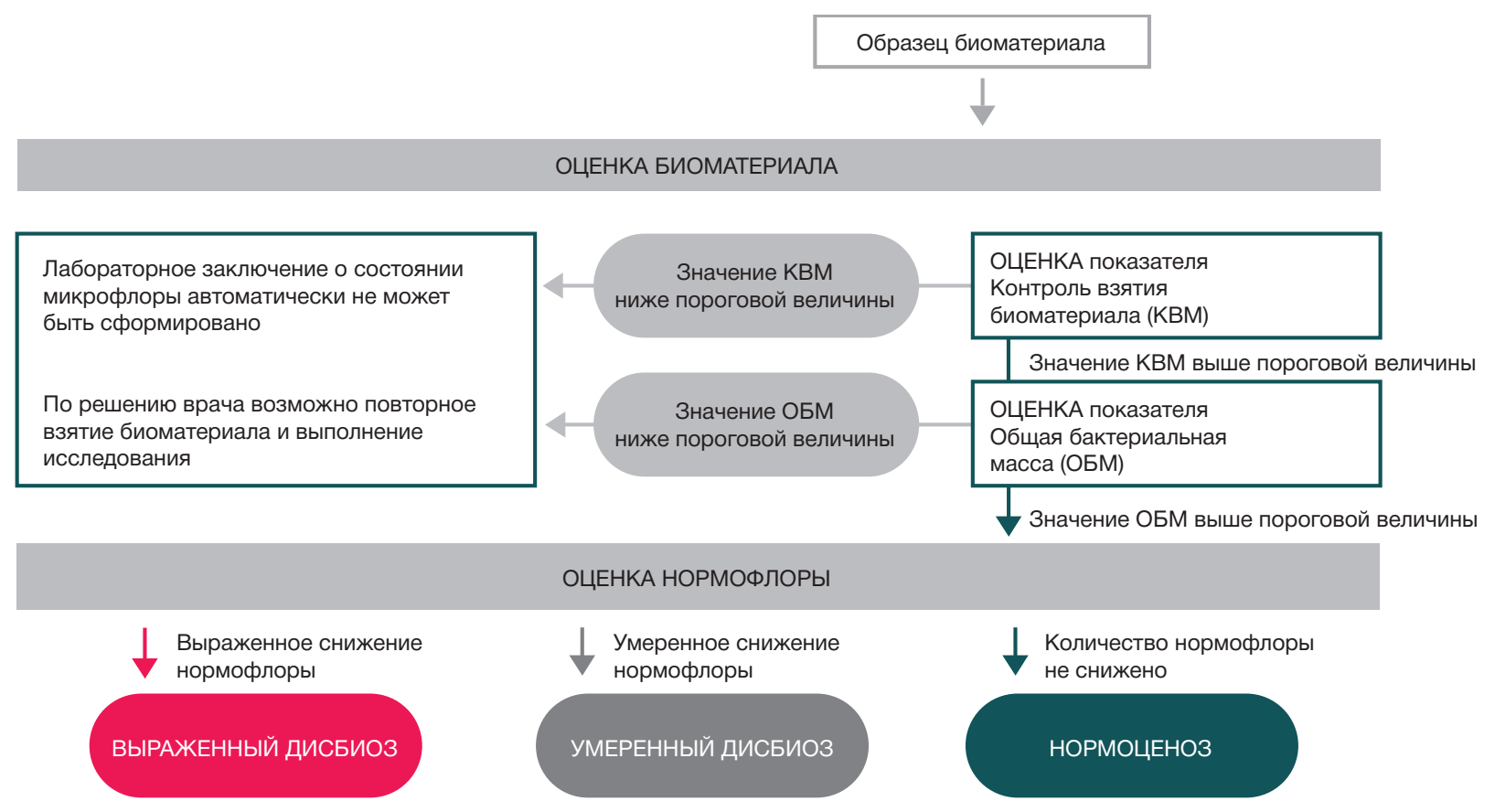

ОЦЕНКА УСЛОВНО-ПАТОГЕННОЙ МИКРОФЛОРЫ

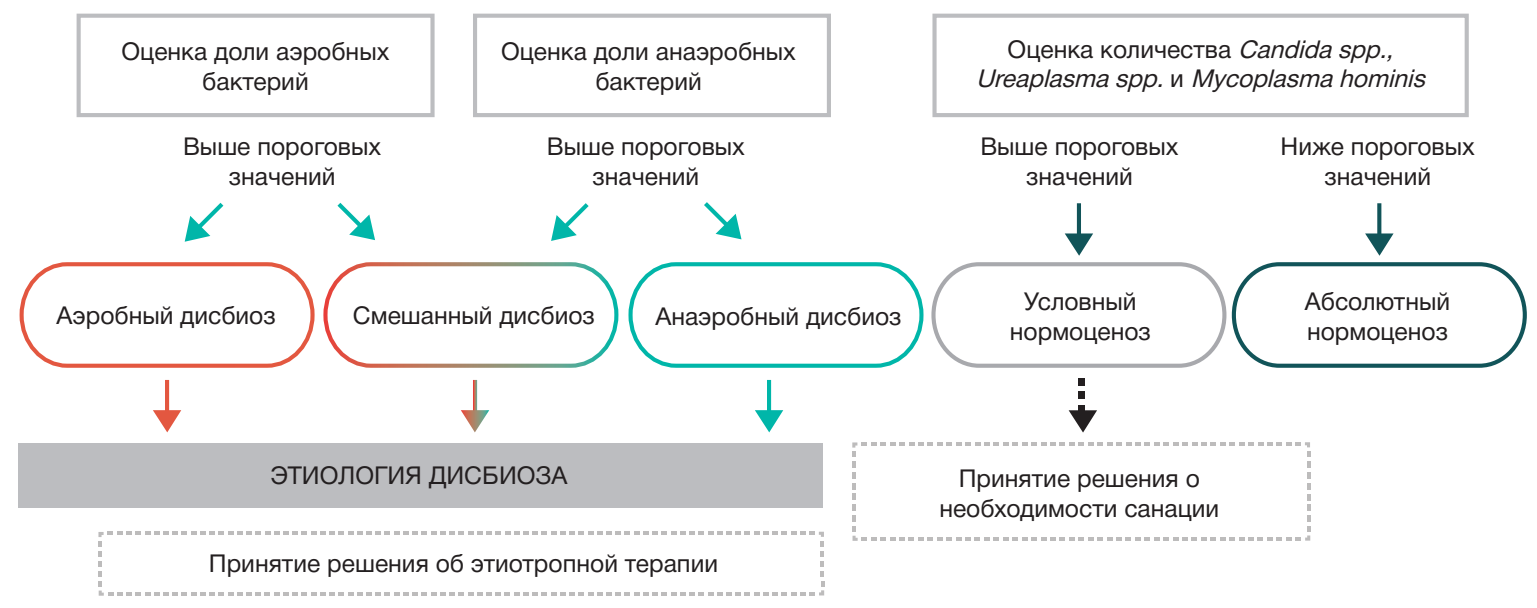

Рис. 1. Принципиальный алгоритм трактовки исследования микрофрлоры урогенитального тракта женщин методом ПцР-РВ 
Чувствительность и специфичность культурального метода во многом зависят от состава питательных сред и от условий культивирования трихомонад. Метод отличается большей трудоемкостью и длительностью выполнения по сравнению с молекулярно-биологическими методами, чувствительность которых составляет 88-97\%, а специсичность - 98-99\%. Применение молекулярнобиологических тестов приоритетно при бессимптомном течении трихомониаза (наиболее часто наблюдающемся у лиц мужского пола), при подозрении на микст-инфекцию, при скрининговых обследованиях, а также для контроля качества микроскопического исследования [5, 8].

Для верификации диагноза хламидийной инфекции, заболеваний, вызванных M. genitalium, и вирусных ИППП (аногенитальной герпесвирусной и папилломавирусной инфекций) рекомендовано применение только молекулярнобиологических методов, обладающих высокими специфичностью и чувствительностью, практически приближающимися к 100\% [5, 9].

Таким образом, молекулярно-биологические методы полимеразная цепная реакция (ПЦР), ПЦР в режиме реального времени (ПЦР-PB), NASBA - регламентированы для диагностики всех инфекций, передаваемых половым путем.

\section{Возможности молекулярно-биологических методов в диагностике патологических состояний урогенитальной системы}

Внедрение метода ПЦР в клиническую практику имело поистине революционное значение для идентификации возбудителей ИППП. Однако на чувствительность исследования методом ПЦР могут влиять неправильно подобранные генетические мишени и/или различные ингибирующие факторы, а проблемы со специфичностью при исследовании могут быть обусловлены присутствием в пробе непатогенных представителей того же рода/семейства микроорганизмов. Кроме того, ПЦР в качественном формате неинформативна для идентификации условнопатогенных микроорганизмов.

Модификацией метода ПЦР, совмещающей амплификацию с одновременной детекцией накопления ее продуктов непосредственно в процессе реакции, является метод ПЦР в реальном времени (ПЦР-PB, или Real-Time PCR), позволяющий не только определять ДНК микроорганизма, но и проводить количественную оценку ее содержания в клинической пробе. ПЦР-РВ не предполагает постамплификационного анализа продуктов реакции и извлечения содержимого пробирок, следовательно, значительно снижается риск контаминации проб, отсутствует необходимость в отдельной лабораторной зоне, сокращается общее время исследования и увеличивается объективность интерпретации его результатов [10].

До недавнего времени идентисиикация условнопатогенных аэробных микроорганизмов была возможна только культуральным методом, а анаэробные микроорганизмы, нередко являющиеся этиологическими агентами воспалительных и дисбиотических заболеваний мочеполовой системы, обнаружить не удавалось. Между тем известно, что эта группа бактерий часто конкурирует с лактобациллами за доминирующее место в биотопе, и при дисбиотических нарушениях у женщин, как правило, именно облигатно-анаэробные микроорганизмы колонизируют вагинальный эпителий [11].

В настоящее время адекватную диагностику ИППП и одновременное выявление дисбиотических состояний (аэробных/анаэробных вагинитов, уретритов, баланопоститов, бактериального вагиноза и др.),

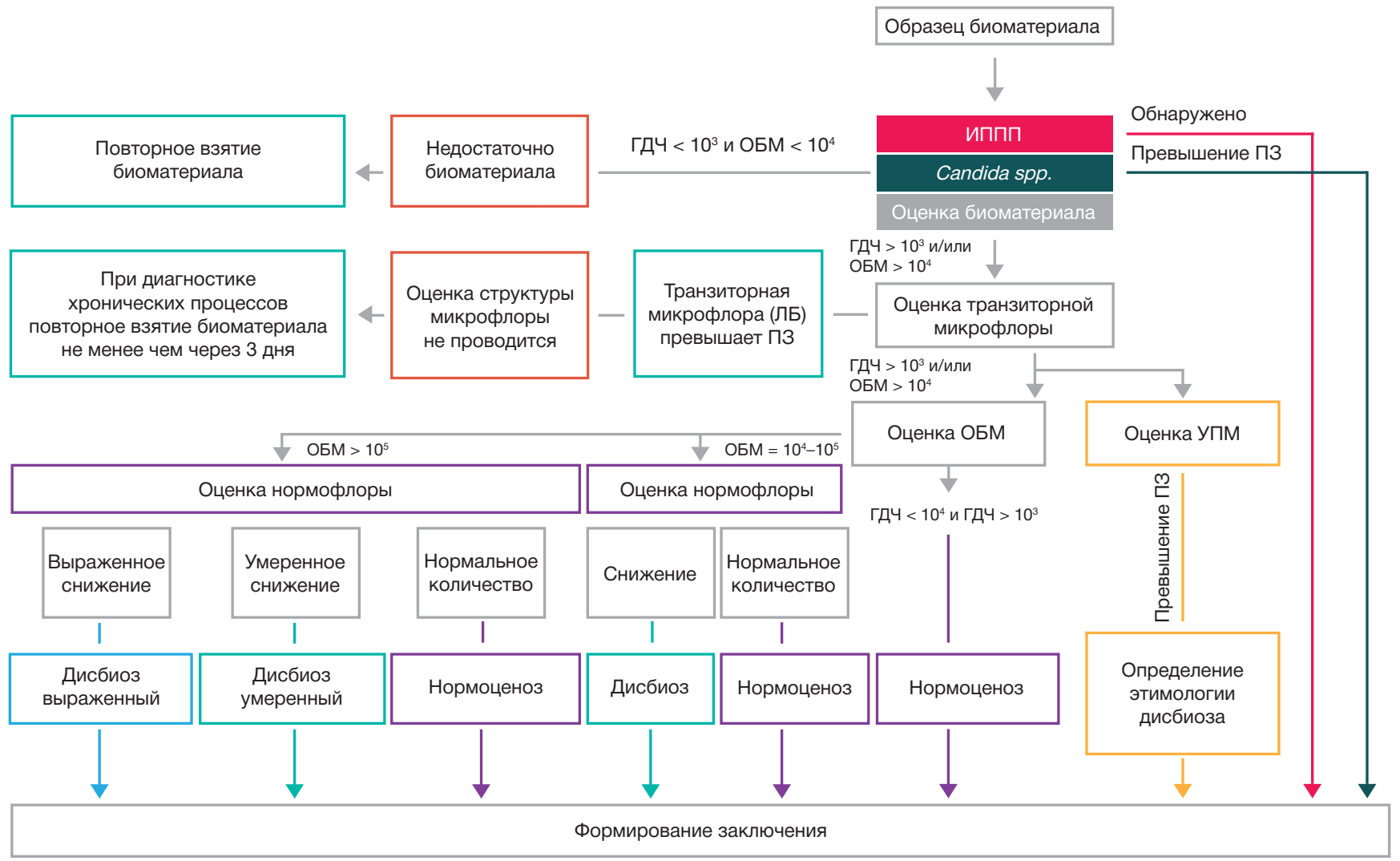

Сокращения: ОБМ - общая бактериальная масса, ГДЧ — геномная ДНК человека, ЛБ - лактобациллы, УПМ - условно-патогенные микроорганизмы, ПЗ — пороговое значение

Рис. 2. Принципиальный алгоритм трактовки исследования микрофлоры урогенитального тракта мужчин методом ПЦР-РВ 
являющихся следствием нарушения баланса между условно-патогенными микроорганизмами и нормальной микробиотой мочеполового тракта, позволяет обеспечить применение метода ПЦР-РВ. На сегодняшний день в России зарегистрирован ряд тест-систем на основе данного метода («Флороценоз», «Амплифлор», «Амплисенс» и др.), позволяющих проводить качественную и количественную оценку патогенных и условно-патогенных аэробных микроорганизмов. Так, тест-системы «Флороценоз» и «Амплифллор" позволяют идентисицировать лактобациллы, представителей рода Candida, семейства Enterobacteriaceae, Streptococcus spp., Staphylococcus spp., G. vaginalis, A. vaginae, условно-патогенные микоплазмы, но не дают возможности определять облигатноанаэробные микроорганизмы. Из всех имеющихся методик наиболее полный спектр условно-патогенных аэробных и анаэробных микроорганизмов представлен в тестах «Фемофлор-16» и «Андрофлор». Применение данных уникальных «парных» тестов, разработанных соответственно для женщин и мужчин, позволяет выработать эффективный алгоритм лабораторного обследования пар и подбора терапии в случае выявления у одного/обоих партнеров заболеваний репродуктивной системы инфекционной этиологии либо нарушений репродуктивной функции (рис. 1, 2) [12, 13].

Одним из важнейших, с клинической точки зрения, параметров данных тестов является контроль качества взятия биоматериала - маркер достаточного количества эпителиальных клеток, попавших в транспортную среду при взятии соскоба. Данный показатель на начальных этапах обследования позволяет оценить адекватность получения биологического материала и избежать ложноположительных и ложноотрицательных результатов исследования [14, 15].

Абсолютные количественные результаты исследования в тестах ПЦР-РВ представляют в геном-эквивалентах
(ГЭ), значения которых пропорциональны микробной обсемененности урогенитального биотопа. Однако, по данным ряда исследователей, абсолютные количественные показатели не всегда коррелируют с выраженностью клинической картины заболевания, а превышение их пороговых значений - с наличием клинических проявлений инфекционно-воспалительного процесса. Так, еще в 1986 г. F. J. Roberts выявил уровень бактериурии ниже значимого у 30\% пациентов с выраженными клинически и подтвержденными лабораторно бактериальными инфекциями мочеполовых путей, а в 1987 г. J. A. Kellogg с соавторами установили отсутствие корреляции между клиническими проявлениями уретрита и значимым уровнем бактериурии. В связи с этим наибольший практический интерес представляет определение относительных количественных показателей (долей) условно-патогенных микроорганизмов в виде логарифмической разницы и в процентах от общей бактериальной массы. Используя данный показатель, специалист имеет возможность оценивать в конкретном биологическом образце долю каждого микроорганизма или группы микроорганизмов, их превалирование над другими видами, в том числе над нормофлорой, что существенно повышает клиническую значимость исследования.

\section{ВЫВОДЬ}

Ранее дискредитированная излишней для урогенитальных патологий сверхчувствительностью ПЦР оправдывает себя благодаря внедрению в рутинную клиническую практику количественных ПЦР-тестов, позволяющих в формате экспресс-анализа комплексно оценивать состояние урогенитального биоценоза. Такой подход демонстрирует соотношение ключевых представителей микробного сообщества, снижая долю ложноположительных и ложноотрицательных результатов.

\section{Литература}

1. Ye H, Song T, Zeng X, Li L, Hou M, Xi M. Association between genital mycoplasmas infection and human papillomavirus infection, abnormal cervical cytopathology, and cervical cancer: a systematic review and meta-analysis. Arch Gynecol Obstet. 2018 Jun; 297 (6): 1377-87.

2. Глобальная стратегия сектора здравоохранения по инфекциям, передаваемым половым путем. 2016-2021 гг. World Health Organization, 2016. Доступно по ссылке: http://www.who.int/ mediacentre/factsheets/fs 110/ru/

3. Khan J, Farzand R. Prevalence of Mycoplasma hominis and Ureaplasma urealyticum among women with unexplaind infertility with and without vaginitis and cervicitis. African Journal of Microbiology Research. 2011; 5 (8): 861-4.

4. Красносельских Т. В., Манашева Е. Б., Гезей М. А. Коморбидность сисилиса и ВИЧ-инфекции: отрицательный эпидемиологический и клинический синергизм. ВИЧинфеекция и иммуносупрессии. 2018; 10 (3): 7-16.

5. Клинические рекомендации по ведению больных инфекциями передаваемыми половым путем, и урогенитальными инфекциями. М.: ДЭКС-пресс, 2012; 112 с.

6. Долгов В. В., редактор. Клиническая лабораторная диагностика. Учебник в 2-х томах. М.: ООО «Лабдиаг», 2018; $624 \mathrm{c}$

7. European Guideline on the Diagnosis and Treatment of Gonorrhoea in Adults 2012. Доступно по ссылке: http://www. iusti.org/regions/Europe/pdf/2012/ Gonorrhoea_2012.pdf.
8. Sexually Transmitted Diseases Treatment Guidelines, 2015. MMWR, 2015; 64 (3).

9. Lanjouw E, Ouburg S, de Vries HJ, Stary A, Radcliffe K, Unemo M. 2015 European guideline on the management of Chlamydia trachomatis infections. Int J STD AIDS. 2016 Apr; 27 (5): 333-48.

10. Рахматулина М. Р., Шаталова А. Ю. Современные представления о микробиоценозе вагинального биотопа и его нарушениях у женщин репродуктивного возраста. Вестник дерматологии и венерологии. 2009; (3): 38-42.

11. Ворошилина Е. С., Донников А. Е., Плотко Е. Э. Биоценоз влагалища с точки зрения количественной полимеразной цепной реакции: что есть норма? Акушерство и гинекология. 2011; (1): 57-65

12. Болдырева М. Н., Галкина И. С. Андрофлор ${ }^{\oplus}-$ новый метод диагностики заболеваний урогенитального тракта мужчин. Медицинский алфавит. 2016; 3 (282): 40-1.

13. Боровец С. Ю. Диагностическая значимость исследования микрофрлоры эякулята у больных хроническим бактериальным простатитом методом PCR-RT «Андрофлор». Урологические ведомости. 2019; 9 (S): 22-3.

14. Шипицына Е. В., Мартикайнен З. М., Воробьева Н. Е., Ермошкина М. С., Степанова О. С., Донников А. Е., и др. Применение теста Фемофлор для оценки микробиоценоза влагалища. Журнал акушерства и женских болезней. 2009; 58 (3): 44-50.

15. Фомина О. В., Болотина Е. С. Опыт применения тест-системы 
«Фемофлор-скрин» для оценки вагинальной микробиоты. В сборнике: IX Всероссийской научно-практической конференции с международным участием. Молекулярная диагностика 2017; 2017 г. Москва: 379-80.

\section{References}

1. Ye H, Song T, Zeng X, Li L, Hou M, Xi M. Association between genital mycoplasmas infection and human papillomavirus infection, abnormal cervical cytopathology, and cervical cancer: a systematic review and meta-analysis. Arch Gynecol Obstet. 2018 Jun; 297 (6): 1377-87.

2. Global Health Sector Strategy on Sexually Transmitted Infections. 2016-2021. World Health Organization, 2016. Available from: http://www.who.int/mediacentre/factsheets/fs110/ru/

3. Khan J, Farzand R. Prevalence of Mycoplasma hominis and Ureaplasma urealyticum among women with unexplaind infertility with and without vaginitis and cervicitis. African Journal of Microbiology Research. 2011; 5 (8): 861-64.

4. Krasnoselskikh TV, Manasheva EB, Gezey MA. Komorbidnost' sifilisa i VICh-infektsii: otritsatel'nyy epidemiologicheskiy i klinicheskiy sinergizm. VICh-infektsiya i immunosupressii. 2018; 10 (3): 7-16. Russian.

5. Klinicheskie rekomendatsii po vedeniyu bol'nykh infektsiyami, peredavaemymi polovym putem, i urogenital'nymi infektsiyami. M.: DEKS-press, 2012; 112 s. Russian.

6. Dolgov W, redaktor. Klinicheskaya laboratornaya diagnostika. Uchebnik v 2 tomakh. M.: 000 «Labdiag», 2018; 624 s. Russian.

7. European Guideline on the Diagnosis and Treatment of Gonorrhoea in Adults 2012. Aavailable from: http://www.iusti.org/ regions/Europe/pdf/2012/ Gonorrhoea_2012.pdf.

8. Sexually Transmitted Diseases Treatment Guidelines, 2015. MMWR, 2015; 64 (3).

9. Lanjouw E, Ouburg S, de Vries HJ, Stary A, Radcliffe K and

Unemo M. 2015 European guideline on the management of Chlamydia trachomatis infections. Int J STD AIDS. 2016 Apr; 27 (5): 333-48.

10. Rakhmatulina MR, Shatalova AYu. Sovremennye predstavleniya o mikrobiotsenoze vaginal'nogo biotopa i ego narusheniyakh u zhenshchin reproduktivnogo vozrasta. Vestnik dermatologii venerologii. 2009; (3): 38-42. Russian.

11. Voroshilina ES, Donnikov AE, Plotko EE. Biotsenoz vlagalishcha s tochki zreniya kolichestvennoy polimeraznoy tsepnoy reaktsii: chto est' norma? Akusherstvo i ginekologiya. 2011; (1): 57-65. Russian.

12. Boldyreva MN, Galkina IS. Androflor ${ }^{\circledR}$ - novyy metod diagnostiki zabolevaniy urogenital'nogo trakta muzhchin. Meditsinskiy alfavit. 2016; 3 (282): 40-1. Russian.

13. Borovets SYu. Diagnosticheskaya znachimost' issledovaniya mikroflory eyakulyata u bol'nykh khronicheskim bakterial'nym prostatitom metodom PCR-RT «Androflor». Urologicheskie vedomosti. 2019; 9 (S): 22-3. Russian.

14. Shipitsyna EV, Martikaynen ZM, Vorobeva NE, Ermoshkina MS, Stepanova OS, Donnikov AE, i dr. Primenenie testa Femoflor dlya otsenki mikrobiotsenoza vlagalishcha. Zhurnal akusherstva i zhenskikh bolezney. 2009; 58 (3): 44-50. Russian.

15. Fomina OV, Bolotina ES. Opyt primeneniya test-sistemy «Femoflor-skrin» dlya otsenki vaginal'noy mikrobioty. V sbornike: IKh Vserossiyskoy nauchno-prakticheskoy konferentsii s mezhdunarodnym uchastiem. Molekulyarnaya diagnostika 2017. 2017 g. Moskva: 379-80. Russian. 